\title{
Epidemiology of diabetes mellitus among First Nations and non-First Nations adults
}

\author{
Roland Dyck MD, Nathaniel Osgood PhD, Ting Hsiang Lin PhD, Amy Gao BSc, Mary Rose Stang PhD
}

Previously published at www.cmaj.ca

\section{ABSTRACT}

Background: First Nations people in Canada experience a disproportionate burden of type 2 diabetes mellitus. To increase our understanding of this evolving epidemic, we compared the epidemiology of diabetes between First Nations and non-First Nations adults in Saskatchewan from 1980 to 2005.

Methods: We used administrative databases to perform a population-based study of diabetes frequency, incidence and prevalence in adults by ethnic background, year, age and sex.

Results: We identified 8275 First Nations and 82306 nonFirst Nations people with diabetes from 1980 to 2005. Overall, the incidence and prevalence of diabetes were more than 4 times higher among First Nations women than among non-First Nations women and more than 2.5 times higher among First Nations men than among non-First Nations men. The number of incident cases of diabetes was highest among First Nations people aged 40-49, while the number among non-First Nations people was greatest in those aged 70 or more years. The prevalence of diabetes increased over the study period from $9.5 \%$ to $20.3 \%$ among First Nations women and from $4.9 \%$ to $16.0 \%$ among First Nations men. Among non-First Nations people, the prevalence increased from $2.0 \%$ to $5.5 \%$ among women and from $2.0 \%$ to $6.2 \%$ among men. By 2005 , almost $50 \%$ of First Nations women and more than $40 \%$ of First Nations men aged 60 or older had diabetes, compared with less than $25 \%$ of non-First Nations men and less than $20 \%$ of non-First Nations women aged 80 or older.

Interpretation: First Nations adults are experiencing a diabetes epidemic that disproportionately affects women during their reproductive years. This ethnicity-based pattern suggests diverse underlying mechanisms that may include differences in the diabetogenic impact of gestational diabetes.

$\mathrm{T}$ he global epidemic of type 2 diabetes mellitus disproportionately affects indigenous and developing populations. ${ }^{1}$ Although genotypic variants related to energy balance may underlie this epidemic, ${ }^{2}$ the rapid emergence of type 2 diabetes in genetically diverse populations worldwide is most likely caused by environmental factors. Increasing rates of type 2 diabetes among Canada's First Nations people, for example, parallel an epidemic of overweight and obesity that has coincided with socio-cultural disruption and a loss of traditional lifestyles.
In Saskatchewan in 1937, diabetes was not detected among the 1500 First Nations people who underwent a tuberculosis survey. ${ }^{4}$ By 1990, almost 10\% of the province's First Nations adults had diabetes; ${ }^{5}$ by 2006 , the proportion was over $20 \%$, while it remained at about $6 \%$ in the general population. ${ }^{5,6}$ Although an increased prevalence of diabetes among First Nations people has also been documented in other Canadian provinces, ${ }^{3}$ only recently have consistent diabetes case definitions applied to health care system administrative databases been used to compare differences between large populations of First Nations and non-First Nations people. ${ }^{7-9}$

We sought to describe the epidemiology of diabetes in Saskatchewan from 1980 to 2005 . We reasoned that finding ethnicity-based differences in trends and patterns of type 2 diabetes over the longest period reported for a Canadian jurisdiction would help to clarify the underlying mechanisms behind known disparities and translate into more effective diabetes prevention and management initiatives.

\section{Methods}

\section{Study population}

The population of Saskatchewan was about one million people throughout the study period. About $99 \%$ (both First Nations and non-First Nations people) were beneficiaries of a universal health care system and were recorded in the Ministry of Health's insurance registry. ${ }^{10}$ These health care beneficiaries made up the total annual populations for this study, as they have for other population-based research. ${ }^{11,12}$ We subdivided the annual populations into First Nations and nonFirst Nations people. First Nations people are indigenous to Canada and, for the purposes of this study, were identifiable in the Ministry of Health databases as individuals (both those who lived on- or off-reserve) registered under Section 6 of the Indian Act of Canada and who were assigned a 10-digit number in the Indian Registry. ${ }^{13}$ The proportion of all provincial health care beneficiaries represented by registered First Nations people grew from about 5\% to $10 \%$ during the study

From the Departments of Medicine (Dyck), Computer Science (Osgood, Gao) and Community Health and Epidemiology (Dyck, Osgood), University of Saskatchewan, Saskatoon, Sask.; the Department of Statistics (Lin), National Taipei University, Taiwan; and the Ministry of Health (Stang), Government of Saskatchewan, Regina, Sask.

CMAJ 2010. DOI:10.1503/cmaj.090846 
period. ${ }^{14}$ Most people categorized as "non-First Nations" are of European origin but about 5\% are of mixed European and First Nations heritage (Metis). Less than $0.5 \%$ of the nonFirst Nations population are nonregistered First Nations people who are not in the Indian Registry. ${ }^{15}$

This study was approved by the University of Saskatchewan Ethics Review Board.

We identified people with diabetes using a validated algorithm ${ }^{16}$ based on the National Diabetes Surveillance System case definitions. ${ }^{7}$ The case definition required one hospital discharge (hospital separation database), two physician service claims (medical claims database) or a physician service claim followed by a hospital discharge for diabetes (ICD-9 250 or ICD-10-CA E10-E14) within any 730 day period. We excluded diabetes records related to gestational records to ensure that gestational diabetes cases were not counted as diabetes cases.

We defined the diabetes incident year as the first calendar year in which the individual met the diabetes case definition (after two years with no diabetes diagnosis). The incident counts for 2004 and 2005 were underestimated because meeting the case definition required up to two years. For each year after the diabetes incident year, the case was counted as a prevalent case. Annual prevalence counts did not include incident cases. We could not distinguish between types 1 and 2 diabetes, but less than $2 \%$ of patients with new diabetes each year are under age $20,{ }^{17}$ which is the age group with the highest incidence of type 1 diabetes. ${ }^{18}$

\section{Statistical analysis}

We obtained de-identified diabetes incident and prevalent case counts by five-year age group, sex and First Nations status for 1980-2005 from the Ministry of Health. We determined the annual crude, age- and sex-specific and age-standardized incidence and prevalence rates of diabetes for First

Table 1: Case counts and age-standardized incidence of diabetes by sex and ethnic background among adults, 1980-2005

\begin{tabular}{|c|c|c|c|c|c|c|c|c|c|c|}
\hline \multirow[b]{2}{*}{ Year } & \multicolumn{2}{|c|}{$\begin{array}{l}\text { First Nations } \\
\text { women }\end{array}$} & \multicolumn{2}{|c|}{$\begin{array}{l}\text { Non-First Nations } \\
\text { women }\end{array}$} & \multirow[b]{2}{*}{$\begin{array}{l}\text { Incidence ratio } \\
\quad(95 \% \mathrm{Cl})\end{array}$} & \multicolumn{2}{|c|}{$\begin{array}{l}\text { First Nations } \\
\text { men }\end{array}$} & \multicolumn{2}{|c|}{$\begin{array}{c}\text { Non-First Nations } \\
\text { men }\end{array}$} & \multirow[b]{2}{*}{$\begin{array}{c}\text { Incidence ratio } \\
(95 \% \mathrm{Cl})\end{array}$} \\
\hline & No. & Per 1000 & No. & Per 1000 & & No. & Per 1000 & No. & Per 1000 & \\
\hline 1980 & 118 & 22.71 & 1389 & 4.50 & $5.05(4.31-5.91)$ & 79 & 12.06 & 1636 & 5.07 & $2.38(1.97-2.87)$ \\
\hline 1981 & 84 & 15.15 & 1404 & 4.46 & $3.40(2.82-4.09)$ & 69 & 11.24 & 1627 & 5.03 & $2.23(1.83-2.74)$ \\
\hline 1982 & 106 & 19.82 & 1343 & 4.22 & $4.70(3.98-5.54)$ & 88 & 13.43 & 1596 & 4.95 & $2.71(2.27-3.25)$ \\
\hline 1983 & 120 & 21.13 & 1352 & 4.19 & $5.05(4.31-5.90)$ & 89 & 12.48 & 1638 & 5.03 & $2.48(2.07-2.97)$ \\
\hline 1984 & 122 & 23.06 & 1339 & 4.07 & $5.66(4.85-6.61)$ & 90 & 12.11 & 1506 & 4.57 & $2.65(2.22-3.17)$ \\
\hline 1985 & 121 & 22.73 & 1185 & 3.53 & $6.44(5.50-7.53)$ & 86 & 12.59 & 1399 & 4.20 & $3.00(2.50-3.60)$ \\
\hline 1986 & 127 & 22.00 & 1312 & 3.92 & $5.61(4.81-6.53)$ & 104 & 14.62 & 1533 & 4.64 & $3.15(2.67-3.72)$ \\
\hline 1987 & 146 & 21.97 & 1273 & 3.76 & $5.85(5.07-6.75)$ & 117 & 15.72 & 1540 & 4.67 & $3.37(2.87-3.94)$ \\
\hline 1988 & 121 & 16.48 & 1292 & 3.81 & $4.32(3.70-5.06)$ & 114 & 15.43 & 1537 & 4.65 & $3.32(2.83-3.90)$ \\
\hline 1989 & 114 & 13.63 & 1222 & 3.58 & $3.81(3.24-4.47)$ & 105 & 12.32 & 1464 & 4.42 & $2.79(2.36-3.29)$ \\
\hline 1990 & 128 & 16.08 & 1143 & 3.33 & $4.83(4.15-5.63)$ & 89 & 10.22 & 1397 & 4.21 & $2.43(2.03-2.91)$ \\
\hline 1991 & 153 & 17.03 & 1145 & 3.33 & $5.12(4.44-5.90)$ & 102 & 12.37 & 1409 & 4.32 & $2.86(2.42-3.39)$ \\
\hline 1992 & 155 & 19.38 & 1347 & 3.91 & $4.95(4.31-5.70)$ & 117 & 11.55 & 1507 & 4.54 & $2.54(2.17-2.98)$ \\
\hline 1993 & 168 & 19.12 & 1285 & 3.68 & $5.20(4.54-5.95)$ & 127 & 12.75 & 1529 & 4.63 & $2.75(2.37-3.21)$ \\
\hline 1994 & 190 & 17.41 & 1191 & 3.42 & $5.09(4.47-5.78)$ & 134 & 12.81 & 1434 & 4.33 & $2.95(2.55-3.43)$ \\
\hline 1995 & 184 & 16.38 & 1259 & 3.59 & $4.56(4.00-5.19)$ & 150 & 13.37 & 1499 & 4.50 & $2.97(2.58-3.42)$ \\
\hline 1996 & 184 & 15.29 & 1268 & 3.60 & $4.25(3.74-4.84)$ & 137 & 12.42 & 1616 & 4.79 & $2.59(2.24-3.00)$ \\
\hline 1997 & 196 & 15.68 & 1580 & 4.47 & $3.51(3.10-3.97)$ & 159 & 13.26 & 1762 & 5.30 & $2.50(2.18-2.87)$ \\
\hline 1998 & 206 & 16.83 & 1508 & 4.24 & $3.97(3.52-4.49)$ & 203 & 16.73 & 1904 & 5.60 & $2.99(2.64-3.37)$ \\
\hline 1999 & 245 & 19.10 & 1612 & 4.46 & $4.28(3.83-4.80)$ & 208 & 17.08 & 2035 & 5.86 & $2.92(2.59-3.29)$ \\
\hline 2000 & 244 & 19.57 & 1759 & 4.92 & $3.98(3.56-4.45)$ & 202 & 16.38 & 2036 & 5.99 & $2.73(2.42-3.09)$ \\
\hline 2001 & 298 & 19.96 & 1796 & 4.99 & $4.00(3.61-4.44)$ & 216 & 16.28 & 2282 & 6.62 & $2.46(2.19-2.76)$ \\
\hline 2002 & 280 & 18.06 & 1974 & 5.42 & $3.33(3.00-3.70)$ & 246 & 17.73 & 2504 & 7.26 & $2.44(2.19-2.73)$ \\
\hline 2003 & 263 & 17.95 & 1883 & 5.29 & 3.39 (3.05-3.78) & 249 & 17.80 & 2315 & 6.77 & $2.63(2.36-2.93)$ \\
\hline $2004 *$ & 250 & 18.23 & 1956 & 5.44 & $3.35(3.00-3.74)$ & 245 & 18.49 & 2311 & 6.67 & $2.77(2.48-3.09)$ \\
\hline $2005^{*}$ & 223 & 13.43 & 1585 & 4.32 & $3.11(2.76-3.50)$ & 203 & 14.81 & 1886 & 5.44 & $2.72(2.41-3.07)$ \\
\hline Total & 4546 & & 37403 & & & 3729 & & 44903 & & \\
\hline
\end{tabular}

Note: $\mathrm{Cl}=$ confidence interval.

* Case counts and incidence are underestimated for 2004 and 2005 because the case definition required up to 2 years. 
Nations and non-First Nations adults (aged $\geq 20$ years). For diabetes prevalence calculations, we included all Ministry of Health beneficiaries in the denominator. ${ }^{10,14}$ To calculate diabetes incidence, we first subtracted prevalent diabetes cases. Age-standardized rate calculations used the direct method standardized to the 1991 Canadian census population. We compared the rates in First Nations and non-First Nations people by calculating annual incidence and prevalence rate ratios.

\section{Results}

Of the 90581 cases of incident diabetes from 1980 to 2005 (Table 1), 8275 were in First Nations people (45\% men) and 82306 were in non-First Nations people (55\% men). Overall, the incidence (Table 1) and prevalence (Table 2) were more than 4 times higher among First Nations women than among non-First Nations women and more than 2.5 times higher among First Nations men than among non-First Nations men.
The highest diabetes rates were among First Nations women, while non-First Nations women had the lowest rates (Figure 1, Figure 2). There was a slight convergence in diabetes rates between First Nations men and women over time, which was associated with a decrease in the incidence of diabetes among women and an increase among men. However, the prevalence of diabetes remained more than $25 \%$ higher among First Nations women than among First Nations men by 2005. From 1980 to 2005, the prevalence of diabetes more than doubled among First Nations women $(9.51 \%$ to $20.33 \%$ ) and more than tripled among First Nations men (4.94\% to $16.01 \%)$. Among non-First Nations people, the rates of change were similar, with an increase from $2.01 \%$ to $5.51 \%$ among women and from $2.01 \%$ to $6.24 \%$ among men.

Figure 3 shows the age-specific diabetes incident case counts and incidence over time. The most consistent finding was a progressive increase in the number of new cases within each age group between 1980 2005. Exceptions were older non-First Nations adults who experienced a slight decline in

Table 2: Case counts and age-standardized prevalence of diabetes by sex and ethnic background among adults, 1980-2005

\begin{tabular}{|c|c|c|c|c|c|c|c|c|c|c|}
\hline \multirow[b]{2}{*}{ Year } & \multicolumn{2}{|c|}{$\begin{array}{l}\text { First Nations } \\
\text { women }\end{array}$} & \multicolumn{2}{|c|}{$\begin{array}{c}\text { Non-First Nations } \\
\text { women }\end{array}$} & \multirow[b]{2}{*}{$\begin{array}{c}\text { Prevalence ratio } \\
(95 \% \mathrm{Cl})\end{array}$} & \multicolumn{2}{|c|}{$\begin{array}{c}\text { First Nations } \\
\text { men }\end{array}$} & \multicolumn{2}{|c|}{$\begin{array}{c}\text { Non-First Nations } \\
\text { men }\end{array}$} & \multirow[b]{2}{*}{$\begin{array}{l}\text { Prevalence ratio } \\
\quad(95 \% \mathrm{Cl})\end{array}$} \\
\hline & No. & Per 100 & No. & Per 100 & & No. & Per 100 & No. & Per 100 & \\
\hline 1980 & 532 & 9.51 & 6601 & 2.01 & $4.72(4.62-4.83)$ & 323 & 4.94 & 6933 & 2.01 & $2.46(2.39-2.54)$ \\
\hline 1981 & 635 & 11.10 & 7496 & 2.25 & $4.94(4.84-5.04)$ & 387 & 5.76 & 8058 & 2.31 & $2.50(2.43-2.57)$ \\
\hline 1982 & 695 & 11.73 & 8461 & 2.48 & $4.73(4.64-4.82)$ & 449 & 6.41 & 9138 & 2.59 & $2.48(2.41-2.54)$ \\
\hline 1983 & 781 & 12.73 & 9311 & 2.68 & $4.75(4.67-4.84)$ & 522 & 7.30 & 10158 & 2.85 & $2.56(2.50-2.62)$ \\
\hline 1984 & 883 & 14.00 & 10123 & 2.86 & $4.90(4.82-4.99)$ & 594 & 8.06 & 11168 & 3.09 & $2.60(2.55-2.66)$ \\
\hline 1985 & 972 & 14.90 & 10903 & 3.02 & $4.93(4.85-5.01)$ & 659 & 8.60 & 11998 & 3.28 & $2.62(2.56-2.67)$ \\
\hline 1986 & 1056 & 15.48 & 11480 & 3.15 & $4.92(4.84-5.00)$ & 711 & 9.11 & 12695 & 3.45 & $2.64(2.59-2.70)$ \\
\hline 1987 & 1151 & 15.81 & 12185 & 3.30 & $4.80(4.72-4.87)$ & 786 & 9.71 & 13418 & 3.61 & $2.69(2.64-2.74)$ \\
\hline 1988 & 1269 & 16.13 & 12794 & 3.42 & $4.71(4.64-4.78)$ & 883 & 10.38 & 14207 & 3.80 & $2.73(2.68-2.78)$ \\
\hline 1989 & 1347 & 15.77 & 13462 & 3.57 & $4.42(4.36-4.49)$ & 969 & 10.84 & 14966 & 3.99 & $2.72(2.67-2.76)$ \\
\hline 1990 & 1425 & 15.82 & 14008 & 3.67 & $4.31(4.25-4.37)$ & 1043 & 11.11 & 15555 & 4.13 & $2.69(2.64-2.73)$ \\
\hline 1991 & 1514 & 16.30 & 14465 & 3.78 & $4.32(4.26-4.38)$ & 1093 & 11.37 & 16012 & 4.27 & $2.67(2.62-2.71)$ \\
\hline 1992 & 1611 & 16.28 & 14900 & 3.84 & $4.24(4.19-4.30)$ & 1156 & 11.49 & 16471 & 4.35 & $2.64(2.60-2.69)$ \\
\hline 1993 & 1726 & 16.71 & 15496 & 3.95 & $4.23(4.17-4.29)$ & 1231 & 11.58 & 17042 & 4.45 & $2.60(2.56-2.64)$ \\
\hline 1994 & 1846 & 17.13 & 15961 & 4.04 & $4.24(4.18-4.29)$ & 1313 & 11.97 & 17603 & 4.59 & $2.61(2.57-2.64)$ \\
\hline 1995 & 1982 & 17.25 & 16303 & 4.09 & $4.22(4.17-4.27)$ & 1391 & 11.99 & 17978 & 4.64 & $2.58(2.55-2.62)$ \\
\hline 1996 & 2124 & 17.43 & 16780 & 4.17 & $4.18(4.13-4.24)$ & 1500 & 12.24 & 18468 & 4.71 & $2.60(2.56-2.64)$ \\
\hline 1997 & 2248 & 17.63 & 17188 & 4.26 & $4.14(4.09-4.19)$ & 1582 & 12.63 & 18989 & 4.84 & $2.61(2.57-2.65)$ \\
\hline 1998 & 2388 & 17.66 & 17857 & 4.38 & $4.03(3.99-4.08)$ & 1694 & 12.74 & 19609 & 4.93 & $2.58(2.55-2.62)$ \\
\hline 1999 & 2531 & 17.81 & 18481 & 4.46 & 3.99 (3.95-4.04) & 1849 & 13.12 & 20395 & 5.04 & $2.60(2.57-2.64)$ \\
\hline 2000 & 2706 & 18.67 & 19170 & 4.68 & $3.99(3.94-4.03)$ & 1981 & 13.80 & 21227 & 5.33 & $2.59(2.56-2.62)$ \\
\hline 2001 & 2869 & 18.77 & 19876 & 4.81 & $3.90(3.86-3.94)$ & 2125 & 14.15 & 21991 & 5.45 & $2.60(2.57-2.63)$ \\
\hline 2002 & 3105 & 19.24 & 20649 & 4.96 & $3.88(3.84-3.92)$ & 2280 & 14.63 & 23042 & 5.65 & $2.59(2.56-2.62)$ \\
\hline 2003 & 3302 & 19.76 & 21623 & 5.20 & $3.80(3.76-3.84)$ & 2460 & 15.46 & 24242 & 5.96 & $2.59(2.56-2.62)$ \\
\hline 2004 & 3478 & 19.95 & 22333 & 5.33 & $3.74(3.70-3.78)$ & 2624 & 15.60 & 25139 & 6.08 & $2.57(2.54-2.59)$ \\
\hline 2005 & 3659 & 20.33 & 23280 & 5.51 & 3.69 (3.65-3.73) & 2791 & 16.01 & 26118 & 6.24 & $2.57(2.54-2.59)$ \\
\hline
\end{tabular}

Note: $\mathrm{Cl}=$ confidence interval. 
the number of diabetes cases in the late 1980s and early 1990s. The most striking difference between First Nations and non-First Nations people was the age at which most new diabetes cases occurred. Those peaked in the 40-49 year age group for both First Nations men and women, while most new cases among non-First Nations people were in the oldest age group ( $\geq 70$ years). There were more diabetes cases in First Nations women than men, particularly during the reproductive years, and there were more diabetes cases among non-First Nations men than women, particularly during middle age and older. Finally, although peak agespecific diabetes incidence and incident case counts both

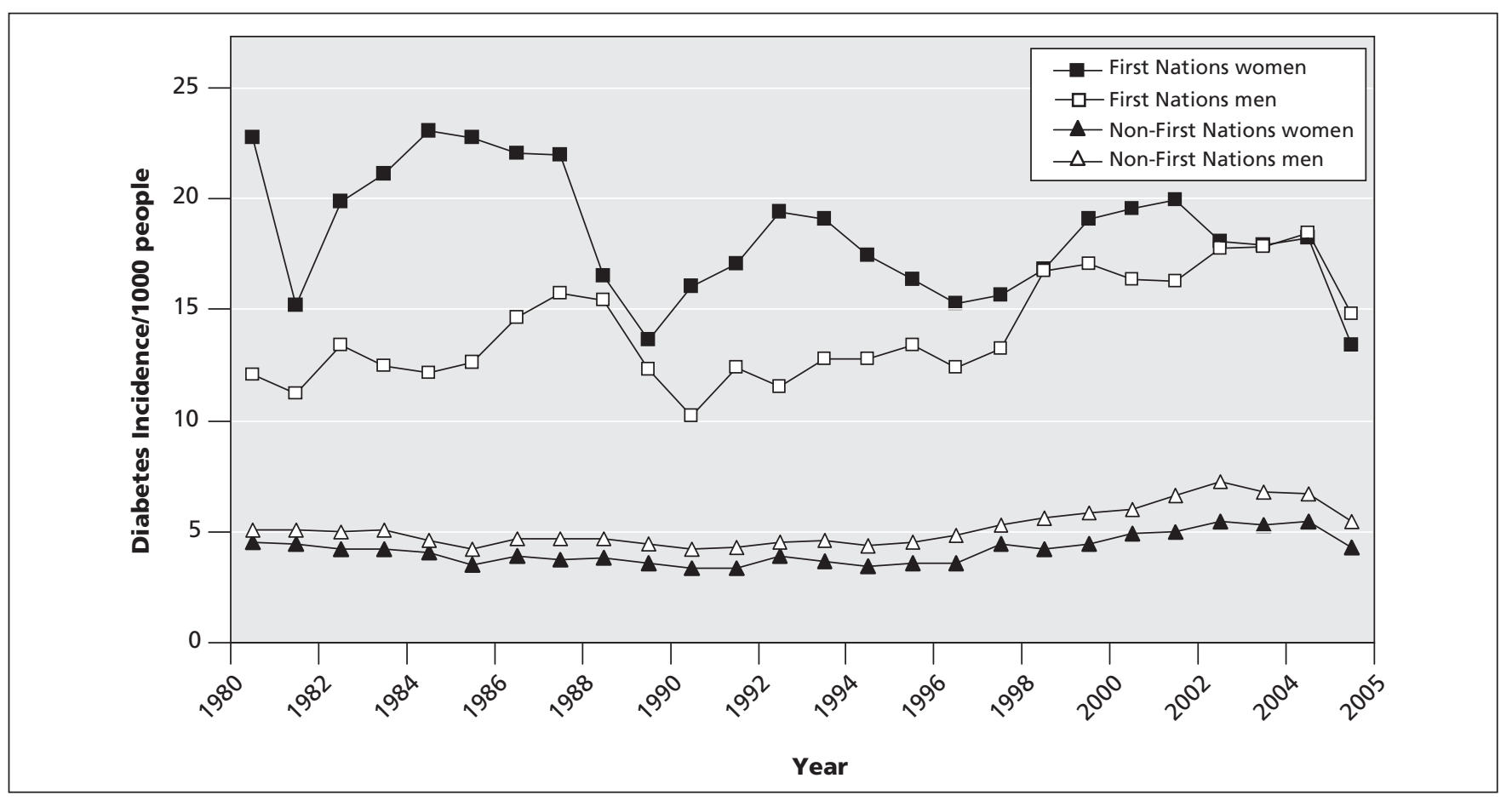

Figure 1: Age-standardized diabetes incidence by ethnic background and sex.

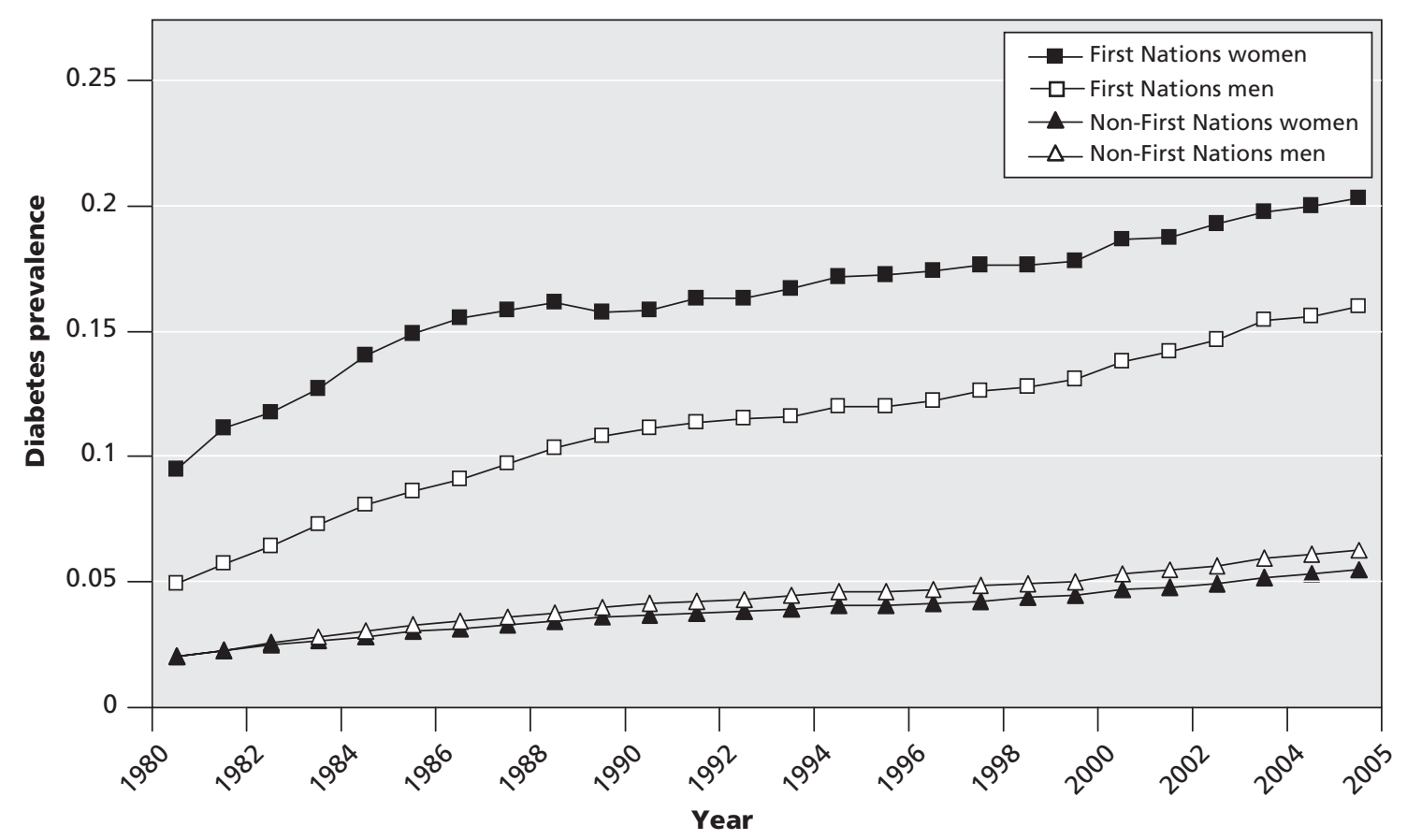

Figure 2: Age-standardized diabetes prevalence by ethnic background and sex. 
occurred in the oldest non-First Nations group ( $\geq 70$ ), there was a 20-year difference between the peak in new diabetes cases (ages 40-49) and incidence (ages 60-69) among First Nations people.

Figure 4 shows that, with few exceptions, there was a progressive increase in the age-specific diabetes prevalence over time in all groups. The largest increases occurred after age 40 among First Nations people and after age 50 among nonFirst Nations people. Among First Nations adults, the prevalence of diabetes was highest between ages 60 and 75. In contrast, the prevalence was highest after age 80 among nonFirst Nations adults. By 2005, almost $50 \%$ of First Nations women and more than $40 \%$ of First Nations men aged 60 and older had diabetes, compared with the highest levels of less than $25 \%$ observed among non-First Nations people aged 80 or older.

\section{Interpretation}

This study describes the epidemiology of diabetes among First Nations and non-First Nations adults over the longest period reported for a Canadian jurisdiction. We found distinct differences between populations that extend beyond known disparities in the rates of diabetes. Thus, diabetes is a disease of young First Nations adults with a marked predilection for women. In contrast, diabetes is a disease of aging non-First Nations adults that is more common among men. These observations suggest fundamental differences between populations in the mechanisms underlying diabetes; this has widespread implications that are probably also relevant to other indigenous and developing populations. ${ }^{1}$

Our findings are consistent with reports that used similar methods ${ }^{8,9}$ to show higher prevalence of diabetes among First Nations people than among non-First Nations people in neighbouring provinces. This difference appears to be at least partly because of higher rates of overweight and obesity among First Nations people. ${ }^{3,19,20}$ Because of a longer study duration and the inclusion of more detailed incidence data, we have now shown that First Nations people also have markedly different trends and patterns of diabetes than non-First Nations people. Among non-First Nations people, the prevalence of diabetes was identical among men and

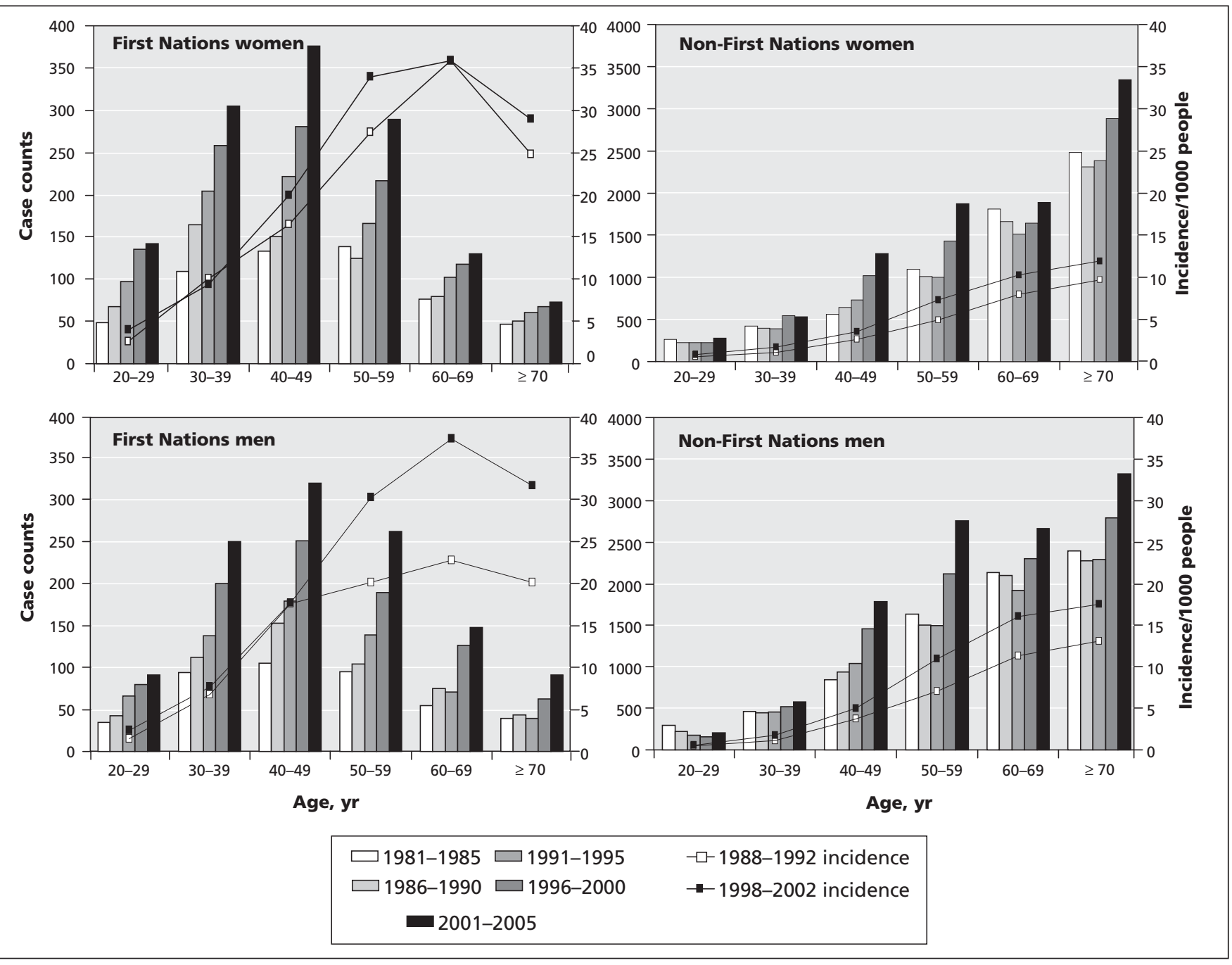

Figure 3: Age-specific diabetes incident case counts and incidence by period. 
women in 1980, but it was substantially higher among men by 2005 . This corresponded to a divergence in the incidence of diabetes between the sexes, which is possibly related to a greater increase in BMI observed in Canadian men than women during this period. ${ }^{21}$ Among First Nations people, the prevalence of diabetes was almost twice as high among women as it was among men in the early 1980s, and a large absolute difference has persisted. Although there was considerable annual variation in the incidence (probably partly because of small numbers), the incidence was consistently higher among First Nations women. Differences in incidence between the sexes have diminished over time, however, and it is possible that the large decrease in diabetes incidence among women in the late 1980s was accentuated by the passage of Bill C-31 in 1985. This primarily reinstated young urban First Nations women to the Indian Registry and would have increased the corresponding study denominators. ${ }^{13}$
Despite very low rates of type 1 diabetes in North American Aboriginal people, ${ }^{18,22}$ most incident cases of diabetes occurred in young First Nations adults. Furthermore, the consistently higher rates of diabetes among First Nations women than among First Nations men was related to an excess burden of diabetes in women aged 20-49. What could account for this striking sex difference? One possibility is the higher rates of overweight and obesity among First Nations women. ${ }^{19,23}$ Another factor may be the high rates of gestational diabetes that were present before the significant occurrence of type 2 diabetes in northern First Nations communities; ${ }^{23}$ gestational diabetes is strongly linked to pre-pregnancy overweight and obesity. ${ }^{24}$ Because gestational diabetes is a predictor for type 2 diabetes in affected women, ${ }^{25}$ female populations with high rates of prepregnancy overweight and obesity and gestational diabetes could experience a resultant intragenerational increase in the rate of type 2 diabetes.

Gestational diabetes has also been implicated in an inter-

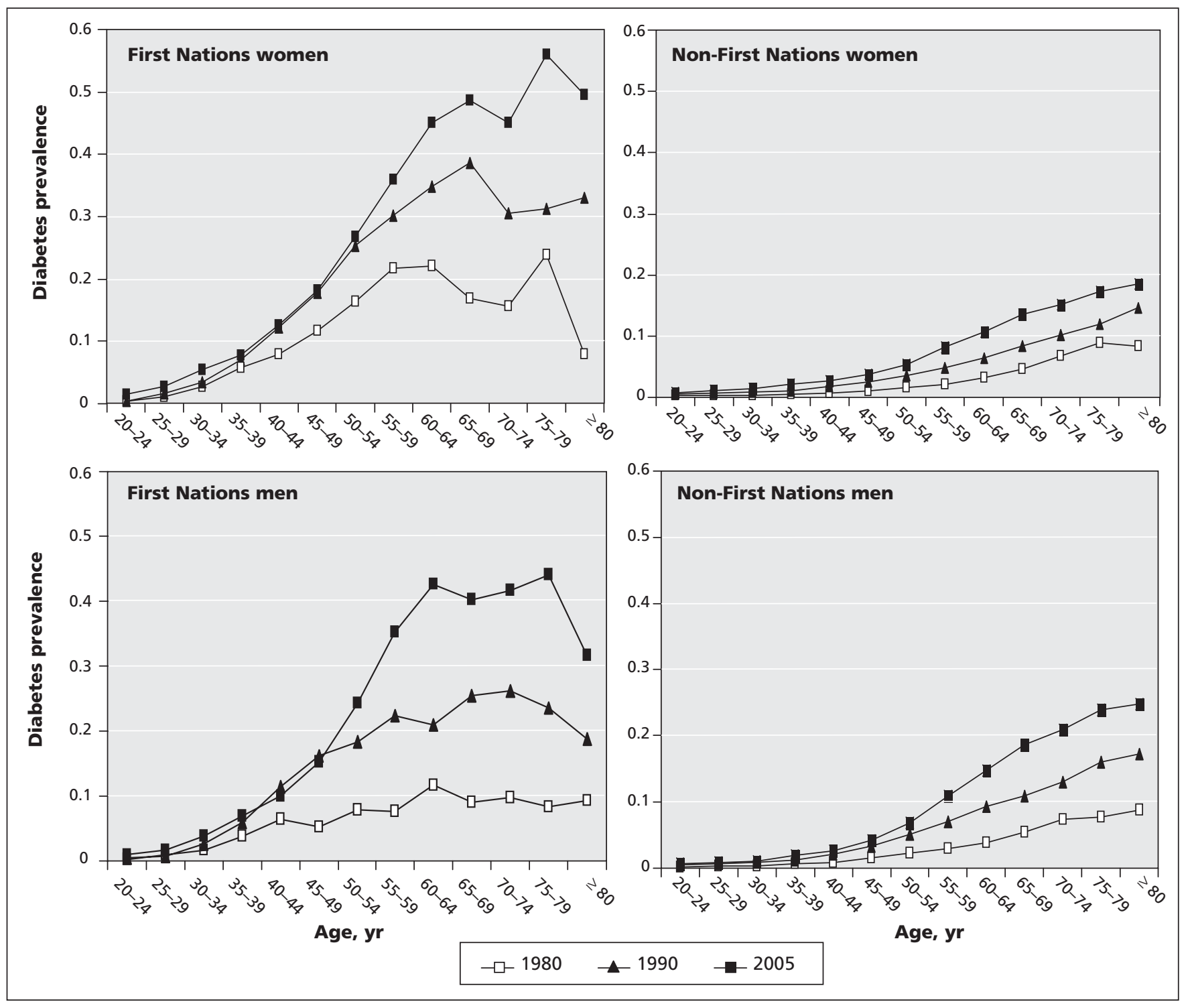

Figure 4: Age-specific diabetes prevalence in 1980, 1990 and 2005. 
generational "vicious cycle" ${ }^{26}$ by increasing the risk of type 2 diabetes among the offspring. ${ }^{22,26}$ This is supported by the early appearance of gestational diabetes among First Nations people ${ }^{23}$ and its association with increasing rates of high birth weight, ${ }^{27}$ a predictor of diabetes among First Nations people..$^{28}$ A recommendation from the Fifth International Workshop on Gestational Diabetes was to clarify the intergenerational diabetogenic role of gestational diabetes. ${ }^{29} \mathrm{We}$ believe that it is equally important to clarify its intragenerational impact and are currently attempting to gain insights into the relative contribution of each through the use of simulation modelling. ${ }^{30}$

The contrasting demographic features of diabetes in First Nations and non-First Nations people have different implications for prevention, screening, management and allocation of health care resources. We highlight three examples. First, with respect to screening and primary prevention initiatives for First Nations people, our findings support an emphasis on children and young adults. ${ }^{31}$ We believe that there is sufficient evidence for both an intra- and intergenerational diabetogenic role of gestational diabetes to focus primary prevention initiatives on the time before and during the reproductive years of First Nations women. Programs designed to prevent gestational diabetes, ensure universal gestational diabetes screening, optimize management of diabetic pregnancies and provide follow-up initiatives for women who have experienced gestational diabetes have the potential to reduce the rate of type 2 diabetes in mothers and their offspring.

Second, the large difference in the age of diabetes onset between First Nations and non-First Nations people could contribute to distinct patterns of chronic complications because of differential mortality and differential exposure to the metabolic effects of diabetes. Although speculative, the duration of exposure to diabetes and its interaction with other variables (e.g., quality of diabetes management) might be an important determinant in the relative likelihood of developing specific diabetic complications such as diabetic end-stage renal disease..$^{32}$ This should also be a priority area for future research.

Finally, the trends reported here indicate that the prevalence of diabetes among both First Nations and non-First Nations people is likely to continue increasing in the foreseeable future, particularly as the large cohort of children and teenagers that make up about half of the First Nations population enter young adulthood. In addition, an earlier "baby boom" among non-First Nations people is approaching the age during which it will also be at the highest risk of diabetes. We are now beginning a period in which two markedly different cohorts will simultaneously experience an increase in diabetes.

\section{Strengths and limitations}

The strengths of this study included its duration, use of a validated algorithm to identify diabetes cases, ${ }^{7,16}$ the use of data for total populations, and the ability to subdivide the population by ethnic background. We are not aware of systematic differences in strategies for diabetes screening or diagnostic criteria between First Nations and non-First Nations people. However, a decrease in diagnostic fasting plasma glucose was widely instituted in $1997^{33}$ and was followed by an expected rise in diabetes incidence in all study groups.

Limitations of the study included an inability to identify Aboriginal people other than First Nations, reducing the true differences between First Nations and non-First Nations people. Second, identifying cases using administrative data is likely to underestimate the incidence and prevalence of diabetes. ${ }^{8,16}$ Third, we could not differentiate between type 1 and type 2 diabetes. However, less than 3\% of all non-First Nations diabetes incident cases occurred among people aged 20-29, the adult group most likely to develop type 1 diabetes. Furthermore, type 1 diabetes is very uncommon among First Nations people, including children. ${ }^{18,21,22}$ Thus, inclusion of type 1 diabetes cases would have only marginally increased the rates of diabetes among non-First Nations people and would have likely reduced the true differences between First Nations and non-First Nations people.

Fourth, some prevalent cases of diabetes may have been misclassified as incident cases at the beginning of the study because of delayed diagnosis or limitations of the algorithm. This could have contributed to the initial decline in diabetes incidence observed in all groups. Finally, we were not able to determine the rate of diabetes by location. However, the rates are currently higher in rural areas ${ }^{34}$ and are consistently lower among northern compared with southern First Nations people. ${ }^{5,8,9}$

\section{Conclusion}

This study shows marked differences in the epidemiology of type 2 diabetes between First Nations and non-First Nations people. Whether this is because of relative differences in the genetics of energy balance interacting with other differences in the environmental determinants of obesity and carbohydrate intolerance is still uncertain. Complicating this further is the emerging possibility that epigenetic phenomena may play a role. ${ }^{35}$ What is clear is that the rapid appearance of type 2 diabetes particularly among First Nations people and other indigenous and developing populations has been precipitated by environmental rather than genetic factors. Its long-term solution will require effective primary prevention initiatives that are population-based and driven by public health and community initiatives.

\section{This article has been peer reviewed.}

Competing interests: None declared.

Contributors: Roland Dyck conceived and designed the study, acquired, analyzed and interpreted the data, and drafted the article. Mary Rose Stang helped design the study and acquired the data. Nathaniel Osgood analyzed and interpreted the data. Ting Hsiang Lin and Amy Gao analyzed the data. Nathaniel Osgood, Ting Hsiang Lin, Mary Rose Stang and Amy Gao revised the manuscript critically for important intellectual content. All of the authors gave final approval of the version submitted for publication.

Acknowledgement: This study is based in part on nonidentifiable data provided by the Saskatchewan Ministry of Health. The interpretations and conclusions of this article do not necessarily represent those of the Government of Saskatchewan or the Saskatchewan Ministry of Health.

Funding: There was no external funding for this study. The Saskatchewan Ministry of Health did not provide funding for this study. 


\section{REFERENCES}

1. Wild S, Roglic G, Green A, et al. Global prevalence of diabetes: estimates for the year 2000 and projections for 2030. Diabetes Care 2004;27:1047-53.

2. Barroso I. Genetics of type 2 diabetes. Diabet Med 2005;22:517-35.

3. Young TK, Reading J, Elias B, et al. Type 2 diabetes mellitus in Canada's First Nations: status of an epidemic in progress. CMAJ 2000;163:561-6.

4. Chase LA. The trend of diabetes in Saskatchewan, 1905 to 1934. CMAJ 1937;36 366-9.

5. Pioro MP, Dyck RF, Gillis DC. Diabetes prevalence rates among First Nations adults on Saskatchewan reserves in 1990: comparison by tribal grouping, geography and with non-First Nations people. Can J Public Health 1996;87:325-8.

6. Klomp H, Chan BTB, Cascagnette PJ, et al. Quality of diabetes management in Saskatchewan: supplementary tables and figures. Saskatoon (SK): Health Quality Council; 2006

7. Public Health Agency of Canada. Diabetes in Canada: Highlights from the National Diabetes Surveillance System, 2004-2005. Ottawa (ON): The Agency; 2008. Available: www.phac-aspc.gc.ca/publicat/2008/dicndss-dacsnsd-0405/index-eng.php (accessed 2009 Nov. 12).

8. Green C, Blanchard JF, Kue Young T, et al. The epidemiology of diabetes in the Manitoba-registered First Nation population: current patterns and comparative trends. Diabetes Care 2003;26:1993-8.

9. Hemmelgarn BR, Toth EL, King M, et al. Diabetes and First Nations people i Alberta: In: Alberta diabetes atlas 2007. Edmonton (AB): Institute of Health Economics; 2007. p. 127-39.

10. Downey W, Stang M, Beck P, et al. Health services databases in Saskatchewan. In: Strom BL, editor. Pharmacoepidemiology. 4th ed. Mississauga (ON): John Wiley \& Sons; 2005. p. 296.

11. Klomp H, Lawson JA, Cockcroft DW, et al. Examining asthma quality of care using a population-based approach. CMAJ 2008;178:1013-21.

12. Pohar SL, Johnson JA. Health care utilization and costs in Saskatchewan's registered Indian population with diabetes. BMC Health Services Research 2007; $7: 126$.

13. Clatworthy SJ. Re-assessing the population impacts of Bill C-31. Ottawa (ON): Indian and Northern Affairs Canada; 2004.

14. Saskatchewan Health covered population 2007. Regina (SK): Saskatchewan Health, Regina; 2007. Available: www.health.gov.sk.ca/covered-population2007 /csv.htm (accessed 2009 Nov. 12).

15. Statistics Canada. 2001 census Aboriginal population profiles. Ottawa (ON): Statistics Canada; 2002. Cat. no. 93F0043XIE.

16. Hux JE, Ivis F, Flintoft V, et al. Diabetes in Ontario: determination of prevalence and incidence using a validated administrative data algorithm. Diabetes Care 2002;25:512-6.

17. Public Health Agency of Canada. Report from the National Diabetes Surveillance System: diabetes in Canada, 2008. Ottawa (ON): The Agency; 2008. Available: www.phac-aspc.gc.ca/ccdpc-cpcmc/ndss-snsd/english/index-eng.php (accessed 2009 Nov. 12).

18. Onkamo P, Väänänen $\mathrm{S}$, Karvonen $\mathrm{M}$, et al. Worldwide increase in incidence of type 1 diabetes - the analysis of the data on published incidence trends. Diabetologia 1999;42:1395-403.

19. Bruner BG, Chad KE, Dyck RF. Prevalence of overweight and obesity in a Woodland Cree community: 14 year trends. Can J Diabetes 2009;33:105-13.
20. Tjepkema M. Measured adult obesity in Canada: measured height and weight. In Nutrition: Findings from the Canadian Community Health Survey. Ottawa (ON): Statistics Canada; 2005. p. 1-32.

21. Katzmarzyk PT. The Canadian obesity epidemic: an historical perspective. Obes Res 2002;10:666-74

22. Young TK, Martens PJ, Taback SP, et al. Type 2 diabetes mellitus in children: prenatal and early infancy risk factors among native Canadians. Arch Pediatr Adolesc Med 2002;156:651-5.

23. Dyck RF, Tan L, Hoeppner VH. Body mass index, gestational diabetes and diabetes mellitus in three northern Saskatchewan Aboriginal communities. Chronic Dis Can 1995;16:24-6.

24. Dyck R, Klomp H, Tan LK, et al. A comparison of rates, risk factors, and outcomes of gestational diabetes between aboriginal and non-aboriginal women in the Saskatoon Health District. Diabetes Care 2002;25:487-93.

25. Feig DS, Zinman B, Wang X, et al. Risk of development of diabetes mellitus after diagnosis of gestational diabetes. CMAJ 2008;179:229-34

26. Pettitt DJ, Knowler WC. Diabetes and obesity in the Pima Indians: a cross-generational vicious cycle. J Obesity Weight Regul 1988;7:61-5.

27. Dyck RF, Tan L. Differences in high birth weight rates between northern and southern Saskatchewan - implications for Aboriginal peoples. Chronic Dis Can 1995;16:107-10

28. Dyck RF, Klomp H, Tan L. From "thrifty genotype" to "hefty fetal phenotype": the relationship between high birth weight and diabetes in Saskatchewan registered Indians. Can J Public Health 2001;92:340-4.

29. Metzger BE, Buchanan TA, Coustan DR, et al. Summary and recommendations of the Fifth International Workshop-Conference on Gestational Diabetes Mellitus. Diabetes Care 2007;30:S251-60.

30. Jones AP, Homer JB, Murphy DL, et al. Understanding diabetes population dynamics through simulation modeling and experimentation. Am J Public Health 2006;96:488-94

31. Macaulay AC, Paradis G, Potvin L, et al. The Kahnawake Schools Diabetes Prevention Project: intervention, evaluation and baseline results of a diabetes primary prevention program with a Native community in Canada. Prev Med 1997;26:779-90.

32. Dyck R, Sidhu N, Klomp H, et al. Linking health care administrative data and laboratory data to study differences in progression of diabetic renal disease in First Nations people and other Saskatchewan residents. 20th World Diabetes Conference; 2009 Oct. 18-20; Montreal (QC). Burssels (Belgium): International Diabetes Federation; 2009.

33. Expert Committee on the Diagnosis and Classification of Diabetes Mellitus. Report of the Expert Committee on the Diagnosis and Classification of Diabetes Mellitus. Diabetes Care 1997;20:1183-97.

34. Klomp H, Cascagnette P, Sidhu N, et al. Quality insight report: diabetes care detailed data tables and figures for all indicators. Saskatoon (SK): Health Quality Council; 2008. Available: www.hqc.sk.ca/hqcQInsight/Diabetes/Diabetes.html (accessed 2009 Nov. 12).

35. Waterland RA, Travisano M, Tahiliani KG, et al. Methyl donor supplementation prevents transgenerational amplification of obesity. Int J Obes (Lond) 2008;32:1373-9.

Correspondence to: Dr. Roland F. Dyck, Department of Medicine, Royal University Hospital, 103 Hospital Dr., Saskatoon SK S7K0P3; roland.dyck@usask.ca 